\title{
OUR CHANGING ATTITUDE TOWARDS GRASS
}

\author{
P. T. Thomas
}

\author{
Welsh Plant Breeding Station, Aberystwyth
}

THE advertisements for New Zealand butter in English newspapers describe your country as a grazier's paradise and readers are encouraged to consume what can be regarded as bottled-up sunshine. I was naturally very anxious to come to a country where grass is so much valued and to appreciate at first hand the striking advances that have been made in grassland research and development. In Britain, we have experienced a changing attitude towards grass and the cereal crop, especially barley, is assuming increasing importance. Associated with this trend has been a greater demand for barley in order to produce carly maturing beef animals. This system, however, which relies almost entirely on barley, is not without serious disadvantages and there are indications of a renewed interest in grass for intensive meat production.

There are, of course, political and economic considerations which account for the differences in approach to farming in Britain and New Zealand but I do not propose to dwell on these. It would, I believe, be of greater mutual interest to consider the differential effects of natural, mainly climatic, factors on the growth of crops and especially on the development of pastures for maximum animal production.

A basic necessity for satisfactory crop production is an adequate amount of solar energy, distributed as far as possible over the whole period of the year. Comparisons show that during what we in Britain call the normal grazing season the quantity of solar radiation compares not unfavourably with that of $\mathrm{New}$ Zealand-about 300 to 400 calories $/ \mathrm{cm}^{2} /$ day. For out of season production, however, we have to be satisfied with less than half the solar energy enjoyed in New Zealand, and during the winter months, the value is usually insufficient for adequate crop response.

Hence, there is the tendency for us to have an increasing interest in the cereal crop which takes full advantage of favourable conditions for the production of more easily conserved fodder as grain. With grass, on the other hand, high peak production during the normal growing season is an embarrassment especially if methods of conservation 
and utilization are inefficient. At Aberystwyth an attempt was made to resolve the problem of uneven production by breeding a series of herbage varieties with different growth rhythms so that direct utilization by the animal could be spread more evenly. In farm practice these varieties have not been fully exploited, primarily because they are often included in relatively complex mixtures and the pastures subjected to indifferent management. They demand to be grown singly or in very simple mixtures so that full advantage can be taken of their differing growth rhythms and other characteristics. An example may be quoted of successful exploitation in which a farmer could graze 85 productive Ayrshire cows on 63 acres of land devoted almost entirely to the persistent high tillering $S_{*_{3}}$ ryegrass. In this instance over 1,200 gallons of milk per acre were produced.

This is probably not a very remarkable performance in good New Zealand conditions, especially as it was achieved only after heavy application of fertilizer amounting to over 400 units of nitrogen per acre (equivalent to nearly 21 cwt of nitro-chalk). Why, then, the difference in production? Assuming that differences in soil and availability of water are not significant, the input of solar energy, both as temperature and light intensity, should again be considered. Here one must differentiate between these two factors, although, of course, they are inter-related in their influence on grass production. The photosynthetic process, which depends on adequate light intensity, involves the production of sugars in the green leaf which are later transformed and used for what is normally regarded as plant growth. In Britain, as compared with $\mathrm{N}$ ew Zealand, there is a greater tendency for accumulation of these sugars in the leaves and this appears to be associated with a lower potential for growth. In actual fact, the differences may be due to the more active use of these sugars for growth in $\mathrm{New}^{\prime}$ Zealand under the influence of a significantly higher temperature in relation to light intensity.

Increased soil fertility will partly compensate for the reduced herbage production obtained when temperature is less than optimum. It will be appreciated, therefore, why in Britain there is an increasing trend towards heavy application of nitrogenous fertilizers which, as has been seen in the example already quoted, can stimulate growth of grass for high production of milk. The 'effect on the pasture, especially under reduced light intensity, is to produce herbage low in sugars and high in protein. Sometimes the value for soluble carbohydrates may be so low that con- 
servation as silage is difficult without addition of molasses. for satisfactory fermentation.

A normal grass/ clover economy for intensive production in Britain suffers on account of the relatively short season of growth for dover - the total yield of herbage being little more than half of that expected from a heavily fertilized and well-stocked pure grass sward. Nevertheless, animal production from grass/ clover mixtures often reach a highly satisfactory level. These considerations have led to some uncertainty in Britain as to the role of clover in farm practice and indeed to an extreme view that it should almost be described as a weed.

A plant breeder must consider all the foregoing problems which have brought about a changing and confusing attitude towards grass. In particular, he must assess the potential for growth in relation to those factors of the environment over which the farmer has no control. Broadly the objectives are to breed varieties which will give satisfactory yields of productive herbage under specified Farming conditions and methods of management.

Our specific objectives at Aberystwyth are pursued through integration and co-ordination of a number of scientific disciplines. Plant introduction and cyto-taxonomy contribute to the store of basic material for the breeder, and new forms are produced by hybridization which is some times associated with duplication of the chromosome number. A department of developmental genetics has been established recently with the primary object of assessing the potential genetic variation in grasses for a number of physiological and biochemical characteristics - especially those which determine the efficiency of conversion of solar energy and soil nutrients to high quality herbage. Tremendous genetic variability can be demonstrated even in established varieties for desirable characters such as photosynthetic activity, growth at low temperature, winter hardiness, digestibility, soluble carbohydrates as well as uptake and utilization of minerals. It should be possible, for example, to select cocksfoots that have as high a digestibility as established perennial ryegrass varieties, but the possibility of even higher values for digestibility in ryegrass is well demonstrated.

Production of genetic material of known physiological characteristics is a vital step in the breeding programme, but it is equally important to assess this material in competitive conditions and to determine how far it conforms, to agronomic models developed as a result of sward performance under different environments and management. 
On the basis of all these studies, coupled with more precise guidance from animal nutritionists, our plant breeders are beginning to have a clearer concept of the kind of herbage varieties which will contribute towards a significant advance in pasture production.

The importance of assessing the potential for growth of varieties and species of grass under reasonably well defined conditions should be re-emphasized. For example, my colleague, Dr Cooper, has been comparing the yearly production for simulated swards of a number of ryegrass varieties under conditions where water and soil nutrients, particularly nitrogen, were not limiting. Defoliation was carried. out in such a way as to keep the herbage as far as possible in the vegetative condition. He showed very significant differences between the growth potential of these varieties and that the very persistent free-tillering types, such a $\mathrm{S} \quad \mathrm{S}_{23}$, really come to their own in responding to adequate soil nutrients and in contrast to the shorterlived stemmy types. Whether they would respond even better in conditions where there is proper cycling of nutrients via the animal, we do not know from precise experiments. The production figures which were mentioned earlier for $S_{z 3}$ were certainly obtained with grazing at a high stocking rate in addition to heavy application of inorganic fertilizers.

This question of cycling of nutrients through the animal is clearly important, and I am most impressed with the attention given in New Zealand to the problem of soil-plantanimal relationship. It is, of course, not a new concept and I vividly recall Sir Bruce Levy preaching its importance in his usual characteristic and effective manner when I was a student with the late Sir George Stapledon at Aberystwyth. For the normally shorter-lived but productive grasses like Italian ryegrass, the importance of biological fertility through the cycling of nutrients via the animal may be even more important than has been realized. Experiments at Aberystwyth have shown that with the variety $S_{22}$ of Italian ryegrass it is true to form in being relatively shortlived when subjected to a cut and carry or zero grazing system of utilization - and this occurs even when adequate amounts of nitrogen, phosphorus 'and potassium are' applied. With full return of dung and urine, on the other, hand, the variety continues to produce very satisfactorily for many years, 
Britain can be described as characteristically a ryegrass country almost to the same extent as New Zealand. But if one looks at growth potential and conversion of solar energy in relation to possible new methods of utilization, the position may have to be reconsidered. My colleague, Dr Hunt, who was working at Grasslands Division as a student with Dr Brougham and now at Aberystwyth, has obtained some interesting comparative data. He has shown that when defoliated at specified levels of light interception, tall fescue is distinctly better in production than ryegrass and other species. It must be emphasized, however, that the material used was highly selected and generalizations are not yet possible. N evertheless, it may be significant that in practice the best production of milk was obtained on a farm where the pasture was $S_{1: 0}$ tall fescue to which over 200 units of nitrogen had been applied, in spite of which, however, a reasonable proportion of white clover was maintained.

This raises the question of the role of clover which, as will be recalled, has almost been described as a weed in Britain. Many years ago the value of white clover for sheep was appreciated by us at A berystwyth, but the recent work in $\mathrm{New}$ Zealand provides most impressive experimental data.

The plant breeder can no longer think in terms of yield of herbage only, but rather the productive capacity of that herbage as meat, milk or wool. Although we are primarily a plant breeding station at Aberystwyth, we have started animal feeding trials as a positive approach to the breeding of improved and productive varieties. Preliminary results are shown (Fig. 1) for the feeding of conserved herbage to bullocks both as hay and as nuts from ground herbage. Conservation under our erratic weather conditions was difficult, and the material was too mature for realistic production studies. Consequently, the differences are due more to digestibility and the physical state of the fodder than to species and varieties. The one remarkable exception was the effect of mixing the very worst and most indigestible grass with $40 \%$ of quite mature red clover. There was no longer a direct relationship with digestibility, and the results clearly demonstrated the productive value of clover.

The results with white clover would probably have been even more striking, and at Aberystwyth we are devoting more attention to the breeding of improved varieties of this species. The work is proceeding in three directions - extension of the growing season, compatibility with grass and effective symbiosis with Rhizobium. As in New Zealand, we 


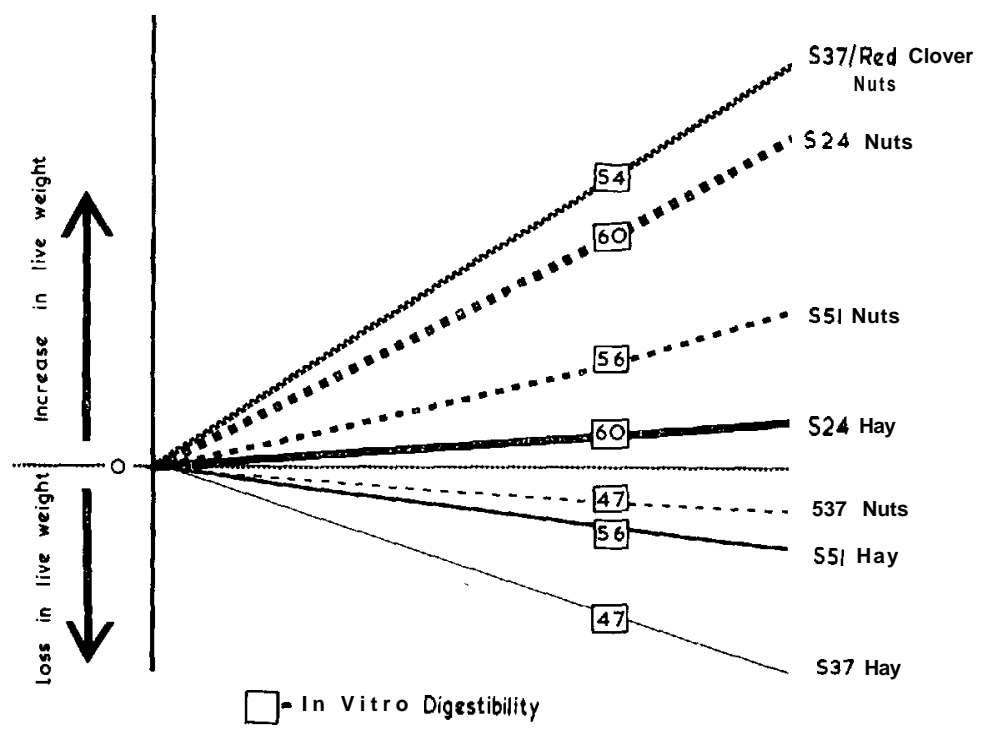

Fig. 1: Diagrammatic summary of preliminary feeding trials.

are crossing indigenous forms with types from Mediterranean countries, and some promising forms are emerging. Compatibility with grass is also important, although careful management will go a long way towards maintaining a desirable grass/ clover ratio. On the efficiency of symbiosis, we find considerable genetic variation both between forms of Rhizobium and between genotypes of clover, so that breeding for effective combinations might well be a practical proposition. Of particular interest to us is the production of rhizobial strains which can be active under conditions of fairly high nitrogen application. So far, one of the most effective strains has been selected from clover which has survived a high rate of applied nitrogen.

Here again, biological fertility may be important because clover will thrive better when there is return of dung and urine. Figure 2 summarizes the different effects of applied nitrogen on grass/ clover swards which appear to relate to the amount of organic return to the pasture. Under a cut and carry system, applied nitrogen has little effect on production until a point is reached when clover no longer contributes to production. With very high stocking rate, on the other hand, and especially if additional organic nutrients are returned in the form of slurry, clover can be 


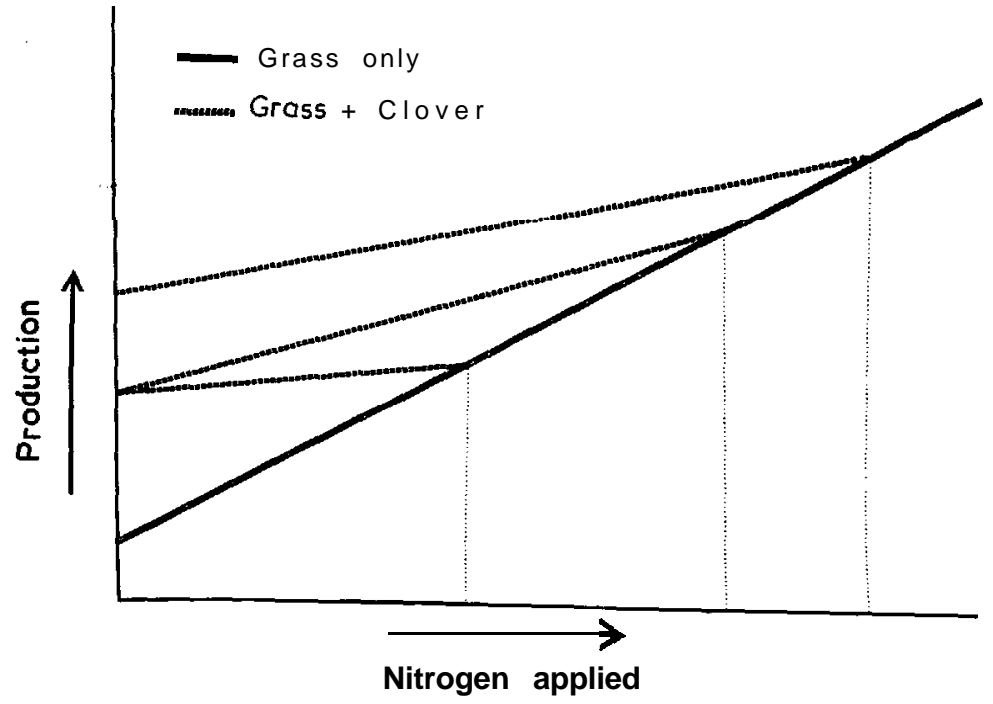

Fig. 2: Effects of applied nitrogen on grass/clover swards which appear to relate to the amount of organic return to the pasture.

successfully maintained in the sward even when the rate of applied inorganic nitrogen is very high.

Returning to grass-breeding, I should like to give one brief glimpse of a promising future development. I have confined my remarks almost entirely to ryegrass and tall fescue, and indicated that the latter may be an important species for extra production. At Aberystwyth we, like others, have attempted to combine these two widely different species and have produced a series of fertile hybrids which show some promise. The fertile hybrid between $\mathrm{S}_{22}$ Italian ryegrass and $S_{t_{i 0}}$ tall fescue, for example, shows many of the desirable characteristics of both parents although the breeder will have considerably more work to do before he can release a stable variety on the market.

A final word to farmers, and especially to those who are increasing land fertility and effectively farming productive pastures instead of merely using extra acres of land I believe you are ready for the next phase in the development of New Zealand agriculture. You will soon be in a position to appreciate fully and to make more effective use of the excellent varieties of grasses and clovers which have been produced here for your benefit. Once you have reached that stage you will also be clamouring for the even more exciting varieties that are now being produced by your plant breeders. 
CHANGING ATTITUDE TOWARDS GRASS

\section{DISCUSSION}

Zero grazing became fashionable in Britain five years ago but we do not hear so much about it now. Would Dr Thomas comment on the position in U.K. now, and its likely application to New Zealand.

The enthusiasm for zero grazing has certainly waned in U.K. for a number of reasons. The high capital and labour costs are important factors, especially when you attempt to restore the biological or organic fertility removed through a cut and carry system. The proper integration of in situ grazing with conservation has been shown to be at least as productive and with less cost.

New Zealand farmers use a varied mixture of plant species in their pastures. Dr Thomus advocates single species sowing. Would he comment on this, please?

Species and varieties have different growth rhythms and for maximum exploitation should be grown separately so that they can be utilized at different times in a complementary manner.

Work at Grasslands Division with tall fescue is similar to that at Aberystwyth. Other countries have recorded information on the lack of acceptability of tall fescue to stock. Has anything been recorded in Britain?

Tall fescue is a grass for good farmers in that it must be superbly managed and utilized before it becomes mnnalatable. When fertility is very high, there is no difficulty with acceptability and the young regrowth is readily consumed.

One of the problems with tall fescue and its crosses in experience at Mussey has been its poor palatability. What comments has Dr Thomas on the palatability of the hybrid he showed on the screen?

The beneficial influence of the Italian rvegrass parent on the hybrid is certainly very evident, although individual plants vary in digestibility from 70 to $80 \%$. Large-scale animal trials have not yet been carried out.

Would Dr Thomas comment on the uptake of magnesium in $S_{170}$ tall fescue? We in New Zealand have experienced metabolic disorders with higher producing grass strains and I wonder if you in Britain have had the same experience.

In general, a higher intensity of animal production is associated with a iendency to metabolic disorders. and the production of barley beef in Britain is a striking example. On the specific question, I can only recall work by Ashton and Sinclair where there was some evidence that the magnesium in tall fescue was more available to the animal than in ryegrass.

In plant breeding, New Zealand workers frequently run into the problem of a conflict of interest in plant characteristics. For instance, one example is a high growth rate with an increasing tendency to stem weevil. To what extent have plant breeders at Aber ystwyth run. into these problems? 
Plant breeders constantly encounter correlations between desirable and undesirable characteristics which they attempt to resolve, or effect a compromise. Fortunately, in Britain, we have not been worried too much by stem weevil and other insect pests, but we are especially concerned with virus and other ill-defined diseases.

\section{What impression has Dr Thomas of the relative carrying capacity of
our hills and flats?}

My impressions are extremely favourable even when I consider that the conditions for growth are better than in Britain. You are now reaping the benefits of the close attention you have given to soilplant-animal relationships.

In the last ten years an aspect of plant breeding has been increasing the chromosome count of plants. Would Dr Thomas comment on the place of these varieties in U.K. at the present time?

No doubt you are referring to the tetraploid ryegrasses which have received considerable publicity. We have reservations about them because it is difficult to demonstrate significant increase in drv matter per acre, but some features such as palatability and soluble carbohydrate content are attractive. Their low dry matter content in a wet dimate is a disadvantage, but this fecture may prove to be in their favour in drier regions.

Speakers some years ago indicated that within ten years Britain would be $100 \%$ converted to barley beef. Now Dr Thomas tells us there is to be more emphasis on grass. What is the resolution of this apparent conflict?

It is difficult to give a straight answer to this question because political and economic considerations involving price support for barley confuse the picture. After the initial impetus for this highly intensive form of production there is now a re-appraisal of the situation, especially after recent work has shown production almost entirely from grass can compete favourably. Ultimately we may find that the complementary use of grass and cereals will be the practical solution. 